\title{
Introduction to Special Issue on Universal Design for Inclusive Pedagogy and a Future Research Agenda
}

\author{
David R. Arendale $\mathbb{D}$ \\ Department of Curriculum and Instruction, University of Minnesota, Minneapolis, MN 55455, USA; \\ arendale@umn.edu; Tel.: +1-612-812-0032
}

Received: 14 November 2018; Accepted: 15 November 2018; Published: 18 November 2018

\begin{abstract}
This Special Issue seeks to address the needs of all postsecondary/tertiary students for a barrier-free learning environment to increase their academic achievement, engagement, learning mastery, and persistence to graduation. Universal Design for Inclusive Pedagogy (UDIP) is sensitive to diverse students and individual differences to promote access and equity. While our colleagues in elementary and secondary education have been addressing this issue for many years, postsecondary education is a newer field for this approach. The six articles in this issue break new ground with regards to expanding the boundaries of Universal Design (UD). Areas explored in this Special Issue are transformed curriculum, innovative teaching and learning practices, cross-national and cross-cultural student interactions, application of UD to academic pathways, and UDIP embedded into the institutional culture and policies. The central themes of the articles are increased access, equity, and social justice for all students.
\end{abstract}

Keywords: universal design; inclusive pedagogy; postsecondary and tertiary access; universal design for learning; universal instructional design; widening access

\section{Introduction}

This Special Issue contributed to identifying needs and providing solutions for overcoming barriers to the learning environment for postsecondary/tertiary students. These articles demonstrated through changed administrative procedures, curriculum, and new approaches that students can increase their academic achievement, engagement, learning mastery, and persistence to graduation through Universal Design for Inclusive Pedagogy (UDIP). UDIP is sensitive to diverse students and individual differences to promote access, equity, and social justice. The authors have provided new and creative ideas for classroom faculty members, student service unit staff, and institutional administrators. While our colleagues in elementary and secondary education have been addressing this issue for many years, postsecondary/tertiary education is a newer field for this approach. As the field has increased in sophistication and nuance, different terms have been introduced. Each often has different approaches, theoretical underpinnings, and specific applications. Some of these include Universal Design (UD) [1], Universal Instructional Design (UID) [2], and Universal Design for Learning (UDL) [3]. Among the articles within this Special Issue, different authors referred to these terms and introduced others. For purposes of this brief introduction, Universal Design (UD) will be the generic term used when referring to these nuanced approaches.

\section{Current Volume}

Many previous publications on UD, UID, UDL, and other similar approaches have often focused on changing the delivery process of learning at the classroom level [4]. Change occurs at the individual faculty member level as they voluntarily modify their teaching processes. Many of these changes 
were based on extending UD principles designed for students with disabilities and embedding them within the class environment for reducing barriers for all students. Articles within this Special Issue extend the traditional approach of these approaches by moving beyond process change within the classroom by implementing a transformed curriculum, new student service/student development approaches, and new administrative policies that expand access for students at the institutional and system level. The authors of this Special Issue challenge the notion that change is dependent upon voluntary action by individual faculty members or student development or service staff members and instead change is required that transforms the learning climate for all students throughout the institution and beyond. Bottom-up change is reflected in changes by the individual faculty and staff members. Top-down change is reflected by administrative changes made by senior administrators and policy-making bodies. These authors provide practical examples of change that begin at the bottom and top of the institution with an eventual transformation of the institutional culture that results in equity and social justice for all.

Ignatian Pedagogy as a Form of UD [5]. Too often, when authors write about UD, it is an unwritten assumption that this is a relatively recent pedagogy. If anything has been learned about education research it is that it is an incremental advancement of previous scholarship. Connecting UD with the Ignatian Pedagogy (IP), which reaches back 500 years, places this "new" UD pedagogy in a larger historical context. Pousson and Myers acknowledge the nuanced differences of the pedagogies but are convincing that the essential elements of UD are already embedded within the IP pedagogical approach. For that reason alone, this is an essential inclusion in the Special Issue. It will challenge readers to reexamine their own understanding of UD and encourage them to make connections with previous and current approaches to pedagogy. This article opens the door to more nuanced scholarship. Another reason for inclusion is the context of Roman Catholic Jesuit institutions. No doubt there are journals devoted to the examination of IP, but few if any articles appear in the general education journals. This article opens-up new areas of inquiry by readers that they may have been previously unaware of.

Expanding UD: Implications for Gender Identity and Sexual Orientation [6]. UD was originally developed to overcome barriers to students with disabilities, both seen and unseen. Couillard and Higbee extend UD for students who have been marginalized due to their gender identity and sexual orientation. Classes which are truly inclusive must be welcoming for all students regarding differing identities. Identity barriers can be just as severe as those with students that have often been served through UD. Both the curriculum and the learning process must take the next step in the transformation to eliminate barriers. Couillard and Higbee explore new territory by linking UD with recognizing social identities as potentially another hidden barrier. While the focus of their article is about gender identity and sexual orientation, the same principles could be extended to other identities which have been marginalized in the classroom and elsewhere within the institutional climate. The authors provide numerous actions that could be taken by faculty members, academic advisors, career services counselors, academic support staff, health and wellness service staff, and more. The article includes an especially engaging set of scenarios for application of the proposed changes in curricula and policies. These would be especially useful for discussion by employees as part of a professional development program on this topic. Higbee and Goff [7] have previously edited and contributed to a comprehensive volume regarding this same topic in this journal Special Issue with some of the authors of these articles.

Bridging Countries and Cultures [8]. This article challenges the traditional interpretation of UD. Duranczyk and Pishcherskaia break new ground by stating that multicultural approaches to learning are insufficient. Rather than simply pursuing more traditional approaches, they advance the concept that education is insufficient unless it is a learning community of students from different nations simultaneously studying the same topic in a carefully nuanced fashion. Learning cannot be "inclusive" if it does not include students from different cultures and nations within the same course. Students must increase not only their cultural competence but also their language competence. Their case study involves students in China, the Russian Republic, and the U.S. This certainly is a progressive idea 
not yet embraced by mainstream educators. One of the purposes of this special issue is to push the boundaries of UD. Access to no-cost and low-cost technology permits easy communication among students separated by time and distance.

Extending UD for Learning through Concurrent Enrollment [9]. Concurrent Enrollment (CE) refers to students enrolled in classes that provide both high school and college credit simultaneously through a carefully constructed curriculum that accomplishes goals for both levels of education. Many publications explain how UD can be applied to a particular classroom but little attention has been made to apply the lens of UD to the actual pathway of students through the education pipeline. While the use of CE is prevalent in U.S. secondary schools, Staats and Laster reframed it as an inclusive pathway from secondary to postsecondary/tertiary institutions. Most publications about UD are concerned with modifications to a single classroom learning environment. The authors identify that while CE is prevalent in North American education, participation is limited to a small population of students deemed the most academically prepared. This article expands the scope of UD as an essential pathway for increased access, equity, and social justice for students entering college. Rather than an opportunity for some students, CE is redefined as an essential pathway for students. Failure to provide CE marginalizes nonparticipating students with future opportunities for successful entrance into college. Recognition of this role requires decisions by administrators and governing boards of multiple secondary and postsecondary institutions to devote personnel, resources, and administrative policies to foster and increase this opportunity for all students. This requires system-level UD commitment rather than voluntary action by a few faculty members. This article describes the equity-focused CE program at the authors' institution and includes a qualitative study of the outcomes for the participating faculty members that identified themes related to the mathematics modeling pedagogy and themes of the structure of the CE program itself. The authors leave the reader with the challenge of supporting the status quo of limited CE availability to the privileged or to expand the program to be inclusive of all students traveling the challenging and difficult pathway to college.

Intercultural Pedagogy: A Faculty Learning Cohort [10]. Lee, Poch, Smith, Kelly, and Leopold advocate that the foundations for 21st-century education are cross-national and cross-cultural student interactions in undergraduate courses. While the professional literature is replete with faculty learning communities and teaching circles, the faculty cohorts described in this article required intentionally diverse cohorts subject area expertise, teaching expertise, and skill with intercultural pedagogy. Creating an inclusive classroom for increasing numbers of recent immigrants and international students required significant faculty development toward the facilitation of intercultural interactions within their classes. Serving all students in the class requires well-designed, relevant, and facilitated discussions. Developing a shared vision for the creation of this inclusive environment is a challenge for some faculty members who have enjoyed personal autonomy within their courses. The authors report on several faculty cohorts and the lessons learned from those experiences.

Integrating UD, Culturally Sustaining Practices, and Constructivism [11]. Grier-Reed and Williams-Wengerd describe how their model of integrating UD, culturally sustaining pedagogy, and utilizing a constructivist approach increases learning for postsecondary students. Their model provides practical strategies to confront the barriers of ableism, race, ethnicity, language, gender, and sexual orientation. These barriers result in institutionalized oppression that replicates itself within the campus fabric. The campus climate and system must be redesigned and reimagined. In this article, a constructivist approach examines the inequity and injustice within undergraduate classrooms. The activities described in this article required careful coordination and implementation to combat this toxic environment. Some of these included the Diversity Lab, fishbowl discussions, cultural interviews, and assessments of the process and content of the dialogue among teachers and students. While some previous publications have discussed some of these aforementioned activities, the authors of this article present a comprehensive and nuanced approach that integrate them seamlessly. The authors carefully link theory with choice of the individual course activities and measures. As the authors 
indicated at the beginning of this article, constructing such a nuanced approach to learning requires a complete redesign of the course from the bottom-up.

\section{Future Research Agenda}

The authors of this Special Issue move the field further but much more is needed to extend their work and by other colleagues in this growing field of UDIP transformation. It is healthy to see the proliferation of evidence-based practices for the classroom and student service units at the institution. However, the need is so great that change cannot occur in one classroom or student service unit at a time. In addition to scaling up this bottom-up process of change, the institutional climate must change and help initiate change from the top-down. Unfortunately, there are few examples of such successful practices in the professional literature. More work is needed to provide effective practices at the macro level so others can adapt and adopt them for use at their institutions.

A classic model for organizational and personal change is provided by Kurt Lewin [12]. Professor Kurt Lewin (1890-1947) was one of the early leaders in social psychology and focused his research heavily on organizational dynamics. Lewin's Force Field Analysis (1947) provided a model for understanding the forces that either foster or hinder change. He described a multi-stage process. The first stage involved early leaders dissatisfied with the status quo because of evidence of poor outcomes. The professional literature is already at this stage with varying levels of awareness of the problems and data studies on the impact of students with different levels of abilities, students of multiple and intersecting identities, and students historically excluded from successful experiences in education.

The second stage of this change model occurs when some people "unfreeze" their customary behaviors and implement new ones that either they create or have learned about. These early innovators collect data, formulate models, continue innovation, and share their results within the wider community. The professional literature has numerous examples but needs many more voices and applications of UDIP.

The third stage of the change model involved the senior leadership of the organization that provides a process for people to begin to "freeze" their new behaviors. While the early adopters have implemented the new models, incentives and processes are needed for widespread implementation. There are few reports of senior academic and student affairs leaders creating and leading an institution-wide embedding of UDIP into the fabric of the institution. Deep change cannot depend upon the good will of already overworked and overcommitted instructors and student service staff members. Models of training and mentoring programs are needed for educators to implement UDIP within their domains. The senior leadership must make UDIP part of their regular communication and reflect it in their actions beyond simply listing it among institutional values buried in documents seldom read by anyone. A sustained effort by everyone over years will be required to change the institutional climate to embrace this new approach and value system. This change must withstand the revolving door of senior and intermediate-level administrators.

The final stage of Lewin's model is that the organization must complete the "freezing" process. Tangible rewards by the institution through increased pay for implementing the new behaviors communicates the actual importance of these behaviors. This could occur through embedding UDIP into the annual review process for salary increases. The institution could regularly provide supplemental pay for educators to attend professional development workshops during times when they are not on contract. What are examples of units large or small that have provided incentives for the adoption of UDIP in their domains of influence? The freezing process for embracement of UDIP must be strong enough to withstand the ever-changing senior and intermediate-level leaders, classroom instructors, and student service unit staff. Otherwise, it will soon be replaced by the next priority of the new leaders and teachers. What are examples of this deep institutional commitment to UDIP as part of its core values and behaviors? 
So far these recommendations have focused on the classroom or student service unit and the upper-level of the institution. However, what about in-between these two levels? How has UDIP been reflected with the development of pathways for students between the classrooms and school settings? Has the institution reviewed the potential barriers to student movement between institutions and through degree programs? One article in this volume investigated the essential role of high school-college bridges. While much literature exists about such programs, has it been examined through the lens of UDIP? While much literature is being produced concerning UD at the classroom level, how has the UD lens been focused on undergraduate and graduate degree programs and the invisible barriers that may populate them?

While the professional literature includes evidence-based practices and policies from different countries, more reports are needed to investigate the influence of different cultural contexts, histories, and values for UDIP. Multinational studies would be instructive for illustrating different approaches. Issues of widening access, equity, and social justice may reveal new international perspectives for overcoming historic barriers and victimization through imperialism and occupation by other countries. Education must be reclaimed as a means of liberation for the individual and not for domination by others [13].

Funding: This research received no external funding.

Conflicts of Interest: The Special Issue editor declares no conflict of interest. Authors were invited through an open call through the ES journal website and email listservs with national and international audiences. Additional authors were recruited by the Special Issue editor based on knowledge of their scholarship with Universal Design. All manuscripts were subjected to a rigorous masked review process with multiple reviewers.

\section{References}

1. Burgstahler, S. Universal Design in Postsecondary Education: Process, Principles, and Applications; DO-IT (Disabilities, Opportunities, Internetworking, and Technology); University of Washington: Seattle, WA, USA, 2012; Available online: https:/ / www.washington.edu/doit/universal-design-postsecondary-educationprocess-principles-and-applications (accessed on 16 November 2018).

2. Pliner, S.M.; Johnson, J.R. Historical, theoretical, and foundational principles of Universal Instructional Design in higher education. Equity Excel. Educ. 2004, 37, 105-113. [CrossRef]

3. Rose, D.; Meyer, A. (Eds.) A practical reader in Universal Design for Learning; Harvard Educational Press: Cambridge, MA, USA, 2006.

4. Lawrie, G.; Marquis, E.; Fuller, E.; Newman, T.; Qiu, M.; Nomikoudis, M.; Roelofs, F.; van Dam, L. Moving towards inclusive learning and teaching: A synthesis of recent literature. Teach. Learn. Inq. 2017, 5. [CrossRef]

5. Pousson, J.M.; Myers, K.A. Ignatian Pedagogy as a frame for Universal Design in college: Meeting learning needs of Generation Z. Educ. Sci. 2018, 8, 193. [CrossRef]

6. Couillard, E.; Higbee, J.L. Expanding the scope of Universal Design: Implications for gender identity and sexual orientation. Educ. Sci. 2018, 8, 147. [CrossRef]

7. Higbee, J.L.; Goff, E. (Eds.) Pedagogy and Student Services for Institutional Transformation (PASS-IT): Implementing Universal Design in Higher Education; Regents of the University of Minnesota, Center for Research on Developmental Education and Urban Literacy, College of Education and Human Development: Minneapolis, MN, USA, 2008.

8. Duranczyk, I.; Pishcherskaia, E. Bridging countries and cultures through accessible global collaborations. Educ. Sci. 2018, 8, 199. [CrossRef]

9. Staats, S.; Laster, L.A. Extending Universal Design for learning through concurrent enrollment: Algebra teachers' perspectives. Educ. Sci. 2018, 8, 152. [CrossRef]

10. Lee, A.; Poch, R.; Smith, A.; Kelly, M.D.; Leopold, H. Intercultural pedagogy: A faculty learning cohort. Educ. Sci. 2018, 8, 177. [CrossRef]

11. Grier-Reed, T.; Williams-Wengerd, A. Integrating Universal Design, culturally sustaining practices, and constructivism to advance inclusive pedagogy in the undergraduate classroom. Edu. Sci. 2018, 8, 167. [CrossRef] 
12. Lewin, K. Frontiers in group dynamics: Concept, method and reality in social science; Social equilibria and social change. Hum. Rel. 1947, 1, 5-41. [CrossRef]

13. Freire, P. Pedagogy of the Oppressed; Continuum: New York, NY, USA, 2002; ISBN 0-8264-1276-9.

(c)

(C) 2018 by the author. Licensee MDPI, Basel, Switzerland. This article is an open access article distributed under the terms and conditions of the Creative Commons Attribution (CC BY) license (http:/ / creativecommons.org/licenses/by/4.0/). 